\title{
Intermittent heparin treatment does not induce hypercoagulability in haemodialysed patients
}

\author{
F PUSINERI, A BINI, L MUSSONI, G REMUZZI, AND MB DONATI
}

From the Division of Nephrology, Ospedali Riuniti, Bergamo, Italy and Istituto di Ricerche Farmacologiche 'Mario Negri', Via Eritrea, 62-20157 Milan, Italy

SUMMARY Antithrombin-III (AT-III) and factor VIII coagulant (F VIII:C) and antigenic (F VIII:RA) activities have been studied in nine conservatively treated and 26 dialysed uraemic patients. AT-III levels were not significantly different from those of controls in either group. Among dialysed patients, those who had experienced thrombotic occlusions of the vascular accesses could not be distinguished from the remaining patients on the basis of their AT-III levels. Both F VIII:C and F VIII:RA were slightly higher than in controls in conservatively treated patients, but significantly higher in haemodialysed patients, especially in those who had never experienced thrombotic complications of the vascular accesses. No acute changes were observed in either the AT-III or F VIII:C/F VIII: $R A$ ratio in five patients given heparin therapy during a dialytic session or in the interdialytic period. Thus repeated intermittent heparin treatment does not induce a hypercoagulable state in haemodialysed patients.

Heparin is widely used as an anticoagulant to prevent or delay fibrin deposition on foreign surfaces, and particularly on artificial kidney membranes during haemodialysis in uraemic patients.

These patients, despite their severe bleeding tendency, are at high risk of thrombotic occlusion of the vascular access. ${ }^{1}$ The potential hazards of hypercoagulability in connection with continuous heparin treatment have been discussed recently; $;^{2-5}$ depletion of antithrombin III (AT-III) due to an increased turnover of this physiological inhibitor induced by heparin $^{6}$ is considered important in this respect. ${ }^{2-4}$ Alternatively, it has been proposed that heparin induces a hypercoagulable state by increasing the levels of factor VIII coagulant activity (F VIII:C) which, during anticoagulation, would escape continuous consumption by thrombin. 578

Stimulated by these reports, a number of conflicting results have subsequently been presented on the effect of intermittent, long-term heparin treatment in haemodialysed patients. Different changes in AT-III and factor VIII activities have been reported by various authors, ${ }^{24910}$ but the results are hard to interpret in view of the different methods used (especially for AT-III) and the disparity in size of the patient groups studied.

Moreover, evaluation of changes induced by intermittent heparin therapy in haemodialysed patients

Received for publication 10 December 1979 requires reference groups not only of normal subjects but also of undialysed uraemic patients. The latter have an altered haemostatic system, possibly related to the uraemic condition itself. ${ }^{11-13}$

In order to define whether intermittent treatment with heparin caused hypercoagulability in haemodialysed patients, we measured AT-III levels (by two different methods) and factor VIII activities in a group of 26 patients on maintenance haemodialysis and compared them with a group of control subjects and a group of conservatively treated uraemic patients. Within the group of haemodialysed patients, the possible association between laboratory changes and the occurrence of thrombosis was also investigated.

\section{Patients and methods}

Twenty-six patients (12 female and 14 male, mean age 43.5 years) with chronic renal failure (CRF) (due to chronic glomerulonephritis in 8 , to pyelonephritis in 6 , to polycystic kidney disease in 4 , and to various other diseases in the remaining 8) who had been undergoing maintenance haemodialysis for from 24 to 90 months were studied immediately before a routine dialysis, that is, 68 hours after the end of the last dialytic session. The patients were all receiving 12 $\mathrm{m}^{2}$ hours per week haemodialysis in thrice weekly sessions. The dialyser used was a Coil kidney with cuprophane membrane. Blood flow was more than 300 
$\mathrm{ml} / \mathrm{min}$ and water flow was $500 \mathrm{ml} / \mathrm{min}$. Among these patients, 13 had never suffered from thromboembolic episodes, whereas in the other 13 at least two episodes of thrombotic complications of the vascular access had occurred in the preceding 15 months. Age, sex, haematocrit value, nature of kidney disease, and period of haemodialytic treatment were comparable in these two groups of patients.

Nine patients with advanced CRF (5 male and 4 female, mean age 45 years) were also studied; they had metabolic disturbances similar to those of the haemodialysed patients (serum creatinine levels 10 $20 \mathrm{mg} / 100 \mathrm{ml} ; 884-1768 \mu \mathrm{mol} / \mathrm{l})$ but had never been exposed to heparin or had dialysis. None of the uraemic patients had liver disease. Ten normal subjects ( 4 male and 6 female, mean age 35.0 years) were also studied.

In a subsequent phase of the investigation, five patients with CRF on maintenance haemodialysis (who had not experienced thrombotic occlusion of the vascular access during the preceding 15 months) were studied before and at hourly intervals during a haemodialytic session.

Sodium heparin (Liquemin, Roche, Basel, Switzerland) was administered twice, immediately before the start of dialysis and after 2 hours' treatment (total dosage per patient per dialytic session 4000-7000 IU). These patients were also studied before and at hourly intervals after the administration of heparin during the interdialytic period; heparin was administered to each patient in the same dosage and time schedule as during dialysis.

Informed consent was obtained from all patients, and the research was carried out according to the Declaration of Helsinki and approved by the Human Experimentation Committee of Bergamo Hospital.

Blood was collected in $0.126 \mathrm{M}$ trisodium citrate solution (9 parts blood to 1 part anticoagulant solution). Platelet-poor plasma, obtained as described, ${ }^{14}$ Wwas rapidly frozen at $-20^{\circ} \mathrm{C}$ in small aliquots and thawed at $37^{\circ} \mathrm{C}$ just before testing.

Antithrombin III biological activity was measured by an amidolytic assay using the synthetic substrate Chromozym-TH (Boehringer-Biochemia, Milan, Italy) and expressed as per cent activity based on a reference curve obtained with serial dilutions of pooled plasma from 10 healthy subjects. Antithrombin-III antigen was measured by unidimensional immunoelectrophoresis in antibody-containing gel. ${ }^{15}$ Factor VIII:C was measured by a one-stage assay using a kit from Immuno Diagnostica, Pisa, Italy. ${ }^{16}$ Factor VIII-related antigen (F VIII:RA) was assayed by unidimensional immunoelectrophoresis in antibody-containing gel, as described by the Italian Working Group. ${ }^{17}$ Rabbit antisera to AT-III and to F VIII: RA were obtained from Behringwerke, Hoechst Italia, Scoppito, Italy.

\section{Results}

Table 1 reports the results of coagulation studies in uraemic and control subjects. AT-III levels, determined by biological and immunological techniques, did not differ significantly from control levels in any of the groups studied. Similar levels were found in conservatively treated and dialysed uraemic patients; within the latter group, the patients with previous thrombotic complications could not be distinguished on the basis of their AT-III levels from those who had never suffered from thrombosis of the vascular access. F VIII:C and F VIII:RA were both slightly increased in conservatively treated uraemic patients and were significantly higher in dialysed patients than in controls.

Among the latter, those with a negative history of thrombotic episodes had the highest levels of both activities. In all instances, the increase of both factor VIII activities ranged in the same order of magnitude.

Table 2 sets out the results of coagulation tests in the five patients studied twice, during haemodialysis and during interdialytic administration of heparin.

Table 1 Coagulation studies in uraemic and control subjects (mean $\pm S E M):$ statistical evaluation performed by Duncan's new multiple range test

\begin{tabular}{|c|c|c|c|c|c|c|}
\hline \multicolumn{2}{|c|}{ Group } & \multirow{2}{*}{$\begin{array}{l}N \\
10\end{array}$} & \multicolumn{2}{|l|}{$A T-I I I(\%)$} & \multirow{2}{*}{ 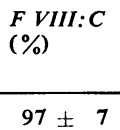 } & \multirow{2}{*}{$\begin{array}{l}\begin{array}{l}F V I I I: R A \\
(\%)\end{array} \\
95 \pm 12\end{array}$} \\
\hline & & & Amidolytic & $\begin{array}{l}\text { Immunological } \\
108 \pm 4\end{array}$ & & \\
\hline $\begin{array}{l}\mathrm{A} \\
\mathrm{B} \\
\mathrm{C} \\
\mathrm{C}_{1} \\
\mathrm{C}_{2}\end{array}$ & $\begin{array}{l}\text { Control } \\
\text { Uraemic undialysed } \\
\text { Dialysed } \\
\text { With thrombotic complications } \\
\text { Without thrombotic complications }\end{array}$ & $\begin{array}{r}10 \\
9 \\
26 \\
13 \\
13\end{array}$ & $\begin{array}{l}120 \pm 4 \\
103 \pm 10 \\
102 \pm 5 \\
103 \pm 10 \\
101 \pm 6\end{array}$ & $\begin{array}{l}108 \pm 4 \\
105 \pm 5 \\
110 \pm 4 \\
107 \pm 3 \\
113 \pm 8\end{array}$ & $\begin{array}{l}97 \pm 7 \\
127 \pm 15 \\
224 \pm 35 \\
190 \pm 47 \\
262 \pm 55\end{array}$ & $\begin{array}{l}95 \pm 12 \\
148 \pm 16 \\
200 \pm 14 \\
164 \pm 15 \\
236 \pm 19\end{array}$ \\
\hline
\end{tabular}

F VIII:C

$A v C_{P}<0.05 ; A v C_{2} P<0.05 ; \mathrm{B} v \mathrm{C}_{2} \mathrm{P}<0.05$.

F VIII: RA

A $v$ B P $<0.05$; A $v$ C P $<0.01$; A $v \mathrm{C}_{1} \mathrm{P}<0.05$; A $v \mathrm{C}_{2} \mathrm{P}<0.01$; $\mathrm{B} v \mathrm{C} \mathrm{P}<0.05$; $\mathrm{B}_{2} \mathrm{P}<0.01$. 
Table 2 Coagulation studies in five patients with chronic renal failure during heparin treatment associated or not with haemodialysis (mean $\pm S E M$ )

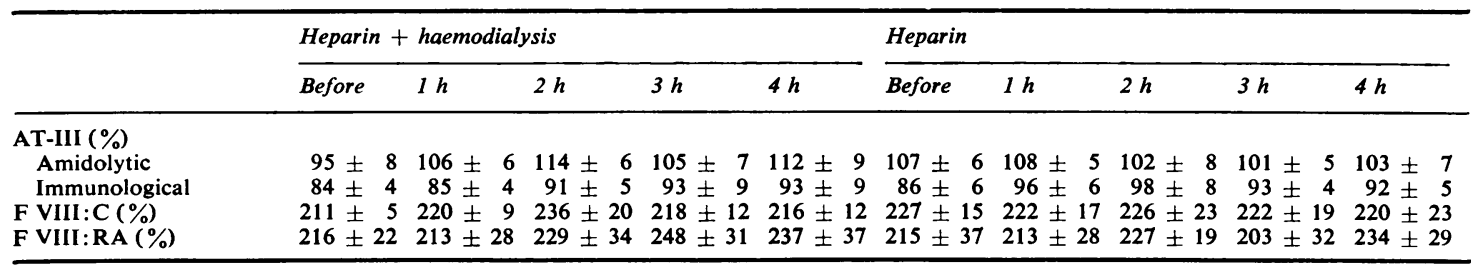

Basal levels of AT-III and factor VIII activities in these patients did not differ significantly from those of the dialysed patients without thrombotic complications. AT-III levels measured at hourly intervals during haemodialysis or during interdialytic heparin administration did not differ significantly from basal levels, nor did either factor VIII activity.

\section{Discussion}

Recent interest has focused on the paradoxically hypercoagulable state induced by continuous treatment with heparin. ${ }^{2-5}$ This could be due to the combination of low AT-III levels and high F-VIII coagulant activity. ${ }^{4}$ Whether such conditions also occur in patients under intermittent heparin therapy during regular haemodialysis has been the subject of debate. ${ }^{24910}$ Our study, extending the findings of Marciniak and Gockerman, ${ }^{2}$ has confirmed that intermittent exposure to heparin, even when it recurred over a long time, did not chronically affect AT-III levels in plasma. Moreover, we found that AT-III levels did not differ significantly at various intervals during heparin administration, associated or not with the dialytic treatment, an observation not apparently described before. The latter finding, together with the normal AT-III levels seen in our conservatively treated uraemic patients, does not support previous indications of higher AT-III levels in uraemic patients who had never been exposed to heparin or had dialysis. ${ }^{9}$

It has been suggested that, in conditions involving intravascular activation of clotting, factor VIII coagulant activity may be destroyed by thrombin, thus leading to a discrepantly high antigen/activity ratio. ${ }^{7} 8$ Heparin, by inhibiting the generation of thrombin, would halt the consumption of F VIII:C. This mechanism could underlie the increase in factor VIII:C reported in haemodialysed patients. ${ }^{5}$ Our finding of higher levels of this activity in dialysed than in conservatively treated uraemic patients might be in line with such a hypothesis. However, in dialysed patients the increase in factor VIII:C was accompanied by a comparable increase in factor VIII:RA, thus making unlikely the assumption of a heparin-induced selective increase in F VIII:C. ${ }^{5}$ The mechanisms of increased F VIII activities in uraemic patients (compared to controls), and particularly in haemodialysed patients, are at present unknown.

In previous studies by other workers and in the experiments described, however, the possible effect of intermittent heparin administration on laboratory parameters suggestive of hypercoagulability was studied by comparing results in undialysed and dialysed patients, the latter known to be exposed to two factors possibly influencing simultaneously the haemostatic system: the passage of blood through the dialysis membrane and the associated heparin treatment.

In order to test further the hypothesis of heparininduced hypercoagulability, we tried to study separately the effects of heparin and dialysis in uraemic patients. In each of five patients with CRF, AT-III and F VIII activities were therefore studied before and during heparin treatment on two occasions, that is, during a routine haemodialytic session and in the interdialytic period. Neither AT-III nor factor VIII levels were modified during heparin administration in either period. These data rule out conclusively the possibility of an absolute or relative decrease in AT-III level ${ }^{9} 10$ being induced by heparin in dialysed patients; moreover, they indicate that high levels of factor VIII activities can be measured in dialysed patients at any interval after the dialytic session and are not acutely influenced by heparin as administered during dialysis.

Our observations, however, did not exclude the possibility that changes in either AT-III or factor VIII activities might play a role in the thromboembolic complications of haemodialysis. ${ }^{9}$

This possibility was investigated by evaluation of AT-III and factor VIII levels in haemodialysed patients who had never suffered thrombotic episodes, and in patients who had had at least two episodes of thrombotic complications of the vascular access during the preceding 15 months. These two groups could not be distinguished on the basis of either AT-III levels or changes in F VIII:C/F VIII:RA ratio. Therefore, the suggestion that decreased 
AT-III levels might play a role in the thromboembolism of uraemic patients ${ }^{9}$ is not borne out by the present data. The reason why both factor VIII activities tended to be lower in haemodialysed patients with previous thrombotic episodes than in those without such complications is not clear. In any case these data do not support the hypothesis of high factor VIII:C as a condition predisposing to thrombotic complications. ${ }^{5}$

In conclusion, our study gives a negative answer to the question whether heparin contributes to hypercoagulability in haemodialysed patients.

This work was supported in part by the Associazione Bergamasca per lo Studio delle Malattie Renali and by a contract from the Italian National Research Council ('Clinical Pharmacology').

We thank Drs G Mecca and G de Gaetano for helpful discussions. The chromogenic substrate Chromozym-TH for antithrombin III assay was kindly provided by Dr P Della Croce, Boehringer Biochemia, Milan, Italy. Judith Baggott, Gigliola Brambilla, and Paola Bonifacino helped to prepare the manuscript.

\section{References}

${ }^{1}$ Kaegi A, Pineo GF, Shimizu A, Trivedi H, Hirsh J, Gent M. Arteriovenous-shunt thrombosis. Prevention by sulfinpyrazone. $N$ Engl J Med 1974;290: 304-6.

2 Marciniak E, Gockerman JP. Heparin-induced decrease in circulating antithrombin-III. Lancet 1977;2:581-4.

${ }^{3}$ O'Brien JR, Etherington MD. Effect of heparin and warfarin on antithrombin III. Lancet 1977;2:1232 (Letter).

4 Editorial: Antithrombin III and heparin. Lancet 1978; 1:538-9.

5 Denson KWE, Redman CWG. Heparin-induced decrease in circulating antithrombin-III. Lancet 1977;2:1028-9 (Letter).
${ }^{6}$ Collen D, Schetz J, de Cock F, Holmer E, Verstraete M. Metabolism of antithrombin III (heparin cofactor) in man: effects of venous thrombosis and of heparin administration. Eur J Clin Invest 1977;7: 27-35.

${ }^{7}$ Denson KWE. The ratio of factor VIII-related antigen and factor VIII biological activity as an index of hypercoagulability and intravascular clotting. Thromb Res 1977;10:107-19.

${ }^{8}$ Redman CWG, Denson KWE, Beilin LJ, Bolton FG, Stirrat GM. Factor-VIII consumption in preeclampsia. Lancet 1977;2:1249-52.

9 Jorgensen KA, Stoffersen E. Venous thrombosis, heparin-induced antithrombin III deficiency, and factor VIII. Lancet 1977;2:1231-2.

${ }^{10}$ Cook MK, et al. Heparin-induced decrease in circulating antithrombin III. Lancet 1978;1:208-9 (Letter).

${ }^{11}$ Rabiner SF. Bleeding in uremia. Med Clins NA 1972; 56:221-33.

${ }^{12}$ Remuzzi G, Livio M, Marchiaro G, Mecca G, and de Gaetano G. Bleeding in renal failure: altered platelet function in chronic uraemia only partially corrected by haemodialysis. Nephron 1978;22:347-53.

${ }^{13}$ Remuzzi G, Schieppati A, Mecca G. Abnormal platelet function in haemodialysed patients: current concepts. Int J Artif Organs 1979;2:109-12.

14 de Gaetano G, Miragliotta G, Roncucci R, Lansen J, Lambelin G. Suloctidil: a novel inhibitor of platelet aggregation in human beings. Thromb Res 1976;8: $361-71$.

${ }^{15}$ Laurell CB. Quantitative estimation of proteins by electrophoresis in agarose gel containing antibodies. Anal Biochem 1966;15:45-52.

${ }^{16}$ Remuzzi G, Livio M, Roncaglioni MC, Mecca G, Donati MB, de Gaetano G. Bleeding in renal failure: is von Willebrand factor implicated ? $\mathrm{Br} \mathrm{Med}$ $J$ 1977; 2:359-61.

${ }^{17}$ Italian Working Group. Spectrum of von Willebrand's disease: a study of 100 cases. Br J Haematol 1977;35: 101-12.

Requests for reprints to: Dr Maria Benedetta Donati, Istituto di Ricerche Farmacologiche 'Mario Negri', Via Eritrea, 62-20157 Milan, Italy. 